\title{
JUURNAL.RU
}

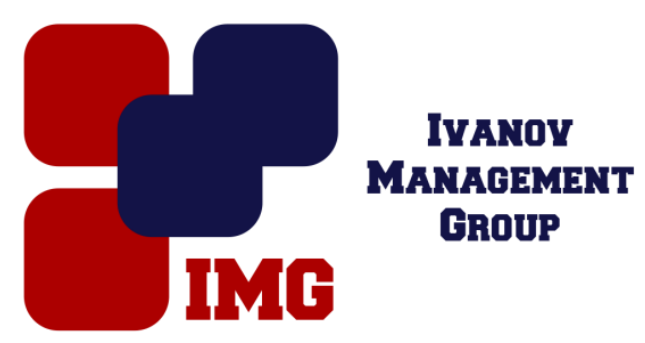

Хайдукова О.И. ГБОУ ВПО СИБГМУ Минздрава России Томск, Россия

doi: $10.18411 / \mathrm{lj}-31-05-2017-63$

idsp 000001:1j-31-05-2017-63

\section{Статистика рынка труда, занятости в Российской Федерации и регионов страны}

\begin{abstract}
Аннотация
В данной статье рассмотрена проблема о разработке новой политики осуществления регулирования занятости. Политика требует, значительных исследований в этой области, например, методы регулирования занятости, децентрализация и централизация, a также повышение эффективности регулирования на региональных уровнях. Проанализированы данные занятости некоторых регионов Российской Федерации и уровень занятости РФ. По результатам исследования динамики численности безработных в Российской Федерации, в среднем за год, было установлено, что показатель безработицы значительно уменьшается. Результаты расчёта относительной величины структуры численности безработных РФ, НО и ТО, показал, что происходят структурные сдвиги в динамике. Показатели среднегодовой численности занятых в экономике РФ, ТО и ОО по видам экономической деятельности показал, что наибольший рост наблюдается в виде экономической деятельности «Транспорт и связь».
\end{abstract}

Ключевые слова: Безработица, рынок труда, занятость населения, рабочие места, карьерный рост, величина заработной платы.

В сфере экономики рынок труда занимает одно из важных мест. Складывающиеся отношения на рынке труда затрагивают потребности большей части населения. Сфера труда - область экономической и социальной жизни общества. В процессе взаимодействия механизмов рынка труда устанавливаются 
оплата труда и уровень занятости населения, получает оценку стоимость рабочей силы, условия труда, найма, получения образования, гарантии занятости, профессионального карьерного роста. Также в сфере рынка труда присутствует немаловажное социально- экономическое, неизбежное явление называемое безработицей, часть трудоспособного населения которого, не может найти себе работу. От занятости населения зависит издержки общества на переподготовку, подготовку, повышение квалификации, уровень жизни людей, на материальную поддержку, лишенных работы, на трудоустройство.

Анализ показателей безработицы и занятости

Таблииа 1. Анализ показателей численности безработных по субъектам РФ, в среднем за год за период с 2000- 2014

\begin{tabular}{|c|c|c|c|c|c|c|c|c|c|c|c|c|c|c|c|}
\hline & $\begin{array}{c}220 \\
00 \\
\end{array}$ & $\begin{array}{c}220 \\
01\end{array}$ & $\begin{array}{c}220 \\
02\end{array}$ & $\begin{array}{c}220 \\
03 \\
\end{array}$ & $\begin{array}{c}2200 \\
4 \\
\end{array}$ & $\begin{array}{c}2200 \\
5 \\
\end{array}$ & $\begin{array}{c}2200 \\
6 \\
\end{array}$ & $\begin{array}{c}220 \\
07 \\
\end{array}$ & $\begin{array}{c}2200 \\
8 \\
\end{array}$ & $\begin{array}{c}2200 \\
9 \\
\end{array}$ & $\begin{array}{c}2201 \\
0 \\
\end{array}$ & $\begin{array}{c}220 \\
11\end{array}$ & $\begin{array}{c}220 \\
12 \\
\end{array}$ & $\begin{array}{c}220 \\
13 \\
\end{array}$ & $\begin{array}{c}220 \\
14 \\
\end{array}$ \\
\hline РФ & $\begin{array}{l}769 \\
9,5\end{array}$ & $\begin{array}{l}642 \\
3,7\end{array}$ & $\begin{array}{c}569 \\
8,3\end{array}$ & $\begin{array}{c}593 \\
3,5\end{array}$ & $\begin{array}{c}5666 \\
, 0\end{array}$ & $\begin{array}{c}5242 \\
, 0\end{array}$ & $\begin{array}{c}5250 \\
, 2\end{array}$ & $\begin{array}{l}451 \\
8,6\end{array}$ & $\begin{array}{c}4697 \\
, 0\end{array}$ & $\begin{array}{c}6283 \\
, 7\end{array}$ & $\begin{array}{c}5544 \\
, 2\end{array}$ & $\begin{array}{l}492 \\
2,4\end{array}$ & $\begin{array}{l}413 \\
0,7\end{array}$ & $\begin{array}{l}413 \\
7,4\end{array}$ & $\begin{array}{c}388 \\
9,4\end{array}$ \\
\hline TO & 68,0 & 51,2 & 59,1 & 69,3 & 54,4 & 54,8 & 47,3 & 37,0 & 43,0 & 46,7 & 41,8 & 46,4 & 41,6 & 39,2 & 41,8 \\
\hline HO & $\begin{array}{c}183, \\
5 \\
\end{array}$ & $\begin{array}{c}162, \\
0 \\
\end{array}$ & $\begin{array}{c}154, \\
1 \\
\end{array}$ & $\begin{array}{c}150, \\
1\end{array}$ & $\begin{array}{c}121, \\
4\end{array}$ & $\begin{array}{c}108, \\
0\end{array}$ & $\begin{array}{c}101, \\
1 \\
\end{array}$ & 97,2 & $\begin{array}{c}105 \\
0\end{array}$ & $\begin{array}{c}141, \\
0\end{array}$ & $\begin{array}{c}109, \\
5\end{array}$ & 98,9 & 80,7 & 84,2 & 73,6 \\
\hline
\end{tabular}

В таблице 1 по данным выборочных обследований населения по проблемам занятости за период с 2000 - 2014 годов. Численность безработных в РФ в 2000 году составило 7699,5 тыс. человек, что на 50,2\% ниже, чем в 2014 году, показатель которого составил 3889,4 тыс. человек. В ТО численность безработных в 2000 году была на 38,5\% меньше, чем в 2014 году. Численность безработных в НО в 2000 году, показатель которого был 183,5, что на 59,9\% ниже, чем в 2014 году.

Таблица 2.

Результаты расчёта относительной величины динамики численности безработных в РФ, в среднем за год

\begin{tabular}{|c|c|c|c|c|c|c|c|c|c|c|c|c|c|c|c|}
\hline & $\begin{array}{c}\mathbf{2 2 0} \\
\mathbf{0 0}\end{array}$ & $\begin{array}{c}\mathbf{2 2 0} \\
\mathbf{0 1}\end{array}$ & $\begin{array}{c}\mathbf{2 2 0} \\
\mathbf{0 2}\end{array}$ & $\begin{array}{c}\mathbf{2 2 0} \\
\mathbf{0 3}\end{array}$ & $\begin{array}{c}\mathbf{2 2 0} \\
\mathbf{0 4}\end{array}$ & $\begin{array}{c}\mathbf{2 2 0} \\
\mathbf{0 5}\end{array}$ & $\begin{array}{c}\mathbf{2 2 0} \\
\mathbf{0 6}\end{array}$ & $\begin{array}{c}\mathbf{2 2 0} \\
\mathbf{0 7}\end{array}$ & $\begin{array}{c}\mathbf{2 2 0} \\
\mathbf{0 8}\end{array}$ & $\begin{array}{c}\mathbf{2 2 0} \\
\mathbf{0 9}\end{array}$ & $\begin{array}{c}\mathbf{2 2 0} \\
\mathbf{1 0}\end{array}$ & $\begin{array}{c}\mathbf{2 2 0} \\
\mathbf{1 1}\end{array}$ & $\begin{array}{c}\mathbf{2 2 0} \\
\mathbf{1 2}\end{array}$ & $\begin{array}{c}\mathbf{2 2 0} \\
\mathbf{1 3}\end{array}$ & $\begin{array}{c}\mathbf{2 2 0} \\
\mathbf{1 4}\end{array}$ \\
\hline $\begin{array}{c}\text { ОВД } \\
\text { базис } \\
\text { ный }\end{array}$ & -- & $\begin{array}{c}00,8 \\
3\end{array}$ & $\begin{array}{c}00,7 \\
4\end{array}$ & $\begin{array}{c}00,7 \\
7\end{array}$ & $\begin{array}{c}00,7 \\
4\end{array}$ & $\begin{array}{c}00,6 \\
8\end{array}$ & $\begin{array}{c}00,6 \\
8\end{array}$ & $\begin{array}{c}00,5 \\
9\end{array}$ & $\begin{array}{c}00,6 \\
1\end{array}$ & $\begin{array}{c}00,8 \\
2\end{array}$ & $\begin{array}{c}00,7 \\
2\end{array}$ & $\begin{array}{c}00,6 \\
4\end{array}$ & $\begin{array}{c}00,5 \\
4\end{array}$ & $\begin{array}{c}00,5 \\
4\end{array}$ & $\begin{array}{c}00,5 \\
1\end{array}$ \\
\hline $\begin{array}{c}\text { ОВД } \\
\text { цепно } \\
\text { й }\end{array}$ & -- & $\begin{array}{c}00,8 \\
3\end{array}$ & $\begin{array}{c}00,8 \\
9\end{array}$ & $\begin{array}{c}11,0 \\
4\end{array}$ & $\begin{array}{c}00,9 \\
5\end{array}$ & $\begin{array}{c}00,9 \\
3\end{array}$ & $\begin{array}{c}11,0 \\
0\end{array}$ & $\begin{array}{c}00,8 \\
6\end{array}$ & $\begin{array}{c}11,0 \\
4\end{array}$ & $\begin{array}{c}11,3 \\
4\end{array}$ & $\begin{array}{c}00,8 \\
8\end{array}$ & $\begin{array}{c}00,8 \\
9\end{array}$ & $\begin{array}{c}00,5 \\
4\end{array}$ & $\begin{array}{c}11,0 \\
0\end{array}$ & $\begin{array}{c}00,9 \\
4\end{array}$ \\
\hline
\end{tabular}

Установлено, что показатель безработицы 2001-2014 годах уменьшается. Можно увидеть, что за 14 лет наименьший показатель составил 0,51 тыс. человек. 
Результаты расчёта относительной величины динамики численности безработных в ТО в среднем за год

\begin{tabular}{|c|c|c|c|c|c|c|c|c|c|c|c|c|c|c|c|}
\hline & $\begin{array}{c}2200 \\
0\end{array}$ & $\begin{array}{c}220 \\
01\end{array}$ & $\begin{array}{c}220 \\
02 \\
\end{array}$ & $\begin{array}{c}220 \\
03 \\
\end{array}$ & $\begin{array}{c}220 \\
04\end{array}$ & $\begin{array}{c}220 \\
05\end{array}$ & $\begin{array}{c}220 \\
06 \\
\end{array}$ & $\begin{array}{c}220 \\
07 \\
\end{array}$ & $\begin{array}{c}220 \\
08 \\
\end{array}$ & $\begin{array}{c}220 \\
09 \\
\end{array}$ & $\begin{array}{c}220 \\
10 \\
\end{array}$ & $\begin{array}{c}220 \\
11 \\
\end{array}$ & $\begin{array}{c}220 \\
12 \\
\end{array}$ & $\begin{array}{c}220 \\
13\end{array}$ & $\begin{array}{c}220 \\
14 \\
\end{array}$ \\
\hline $\begin{array}{c}\text { ОВД } \\
\text { бази } \\
\text { сны } \\
\text { й } \\
\end{array}$ & -- & $\begin{array}{c}00,7 \\
5\end{array}$ & $\begin{array}{c}00,8 \\
7\end{array}$ & $\begin{array}{c}11,0 \\
2\end{array}$ & $\begin{array}{c}11,7 \\
9\end{array}$ & $\begin{array}{c}11,5 \\
7\end{array}$ & $\begin{array}{c}11,4 \\
9\end{array}$ & $\begin{array}{c}11,4 \\
3\end{array}$ & $\begin{array}{c}11,5 \\
4\end{array}$ & $\begin{array}{c}22,0 \\
7\end{array}$ & $\begin{array}{c}11,6 \\
1\end{array}$ & $\begin{array}{c}11,4 \\
5\end{array}$ & $\begin{array}{c}00,6 \\
1\end{array}$ & $\begin{array}{c}00,5 \\
8\end{array}$ & $\begin{array}{c}00,6 \\
1\end{array}$ \\
\hline $\begin{array}{c}\text { ОВД } \\
\text { цепн } \\
\text { ой }\end{array}$ & -- & $\begin{array}{c}00,7 \\
5\end{array}$ & $\begin{array}{c}00,1 \\
5\end{array}$ & $\begin{array}{c}11,1 \\
7\end{array}$ & $\begin{array}{c}00,7 \\
5\end{array}$ & $\begin{array}{c}00,8 \\
9\end{array}$ & $\begin{array}{c}00,9 \\
4\end{array}$ & $\begin{array}{c}00,9 \\
6\end{array}$ & $\begin{array}{c}11,0 \\
8\end{array}$ & $\begin{array}{c}11,3 \\
4\end{array}$ & $\begin{array}{c}00,7 \\
8\end{array}$ & $\begin{array}{c}00,9 \\
0\end{array}$ & $\begin{array}{c}00,4 \\
2\end{array}$ & $\begin{array}{c}00,9 \\
4\end{array}$ & $\begin{array}{c}11,0 \\
7\end{array}$ \\
\hline
\end{tabular}

Установлено, что показатель безработицы 2001-2014 годах уменьшается. Можно увидеть, что за 14 лет наименьший показатель составил 0,61 тыс. человек.

Таблица 4

Результаты расчёта относительной величины динамики численности безработных в Новосибирской области, в среднем за год за период с 2000-2014г

\begin{tabular}{|c|c|c|c|c|c|c|c|c|c|c|c|c|c|c|c|}
\hline & $\begin{array}{c}2200 \\
0\end{array}$ & $\begin{array}{c}220 \\
01\end{array}$ & $\begin{array}{c}220 \\
02\end{array}$ & $\begin{array}{c}220 \\
03 \\
\end{array}$ & $\begin{array}{c}220 \\
04\end{array}$ & $\begin{array}{c}220 \\
05\end{array}$ & $\begin{array}{c}220 \\
06\end{array}$ & $\begin{array}{c}220 \\
\mathbf{0 7} \\
\end{array}$ & $\begin{array}{c}220 \\
08 \\
\end{array}$ & $\begin{array}{c}220 \\
09 \\
\end{array}$ & $\begin{array}{c}220 \\
10 \\
\end{array}$ & $\begin{array}{c}220 \\
11\end{array}$ & $\begin{array}{c}220 \\
12\end{array}$ & $\begin{array}{c}220 \\
13 \\
\end{array}$ & $\begin{array}{c}220 \\
14\end{array}$ \\
\hline $\begin{array}{c}\text { ОВД } \\
\text { бази } \\
\text { сны } \\
\text { й } \\
\end{array}$ & -- & $\begin{array}{c}00,8 \\
9\end{array}$ & $\begin{array}{c}00,8 \\
4\end{array}$ & $\begin{array}{c}00,8 \\
2\end{array}$ & $\begin{array}{c}00,6 \\
7\end{array}$ & $\begin{array}{c}00,5 \\
9\end{array}$ & $\begin{array}{c}00,5 \\
5\end{array}$ & $\begin{array}{c}00,5 \\
3\end{array}$ & $\begin{array}{c}00,5 \\
7\end{array}$ & $\begin{array}{c}00,7 \\
7\end{array}$ & $\begin{array}{c}00,6 \\
0\end{array}$ & $\begin{array}{c}00,5 \\
4\end{array}$ & $\begin{array}{c}00,4 \\
4\end{array}$ & $\begin{array}{c}00,4 \\
6\end{array}$ & $\begin{array}{c}00,4 \\
0\end{array}$ \\
\hline $\begin{array}{c}\text { ОВД } \\
\text { цепн } \\
\text { ой }\end{array}$ & -- & $\begin{array}{c}00,8 \\
8\end{array}$ & $\begin{array}{c}00,9 \\
5\end{array}$ & $\begin{array}{c}00,9 \\
7\end{array}$ & $\begin{array}{c}00,8 \\
1\end{array}$ & $\begin{array}{c}00,8 \\
9\end{array}$ & $\begin{array}{c}00,9 \\
4\end{array}$ & $\begin{array}{c}00,9 \\
6\end{array}$ & $\begin{array}{c}11,0 \\
8\end{array}$ & $\begin{array}{c}11,3 \\
4\end{array}$ & $\begin{array}{c}00,7 \\
8\end{array}$ & $\begin{array}{c}00,9 \\
0\end{array}$ & $\begin{array}{c}00,8 \\
2\end{array}$ & $\begin{array}{c}11,0 \\
4\end{array}$ & $\begin{array}{c}00,8 \\
7\end{array}$ \\
\hline
\end{tabular}

Установлено, что показатель безработицы 2001-2014 годах уменьшается. Можно увидеть, что за 14 лет наименьший показатель составил 0,40 тыс. человек.

Таблица 5.

Результаты расчёта коэффициентов корреляиии за период 2000-2014 г.

\begin{tabular}{|c|c|c|c|}
\hline & РФ и ТО & РФ и НО & ТО и НО \\
\hline $\begin{array}{c}\text { Коэффициент } \\
\text { корреляции }\end{array}$ & 0,9 & 1,0 & 0,9 \\
\hline $\begin{array}{c}\text { Коэффициент } \\
\text { корреляции }\end{array}$ & 10,5 & 10,3 & 10,6 \\
\hline
\end{tabular}

Связь между показателями численности безработных, в среднем за год нелинейная, но, тем не менее, имеется сильная корреляционная зависимость. Можно сделать вывод о том, что самая сильная корреляционная зависимость наблюдается между показателями численности безработицы ТО и $\mathrm{HO}$, а также между РФ и ТО.

Таблица 6. Результаты расчёта относительной величины структуры численности безработных в ТО по отношению к РФ за

\begin{tabular}{|c|c|c|c|c|c|c|c|c|c|c|c|c|c|c|c|}
\hline & $\begin{array}{c}2200 \\
0\end{array}$ & $\begin{array}{c}2200 \\
1\end{array}$ & $\begin{array}{c}2200 \\
2\end{array}$ & $\begin{array}{c}2200 \\
3\end{array}$ & $\begin{array}{c}2200 \\
4\end{array}$ & $\begin{array}{c}2200 \\
5\end{array}$ & $\begin{array}{c}2200 \\
6\end{array}$ & $\begin{array}{c}2200 \\
7\end{array}$ & $\begin{array}{c}2200 \\
8\end{array}$ & $\begin{array}{c}2200 \\
9\end{array}$ & $\begin{array}{c}2201 \\
0\end{array}$ & $\begin{array}{c}2201 \\
1\end{array}$ & $\begin{array}{c}2201 \\
2\end{array}$ & $\begin{array}{c}2201 \\
3\end{array}$ & $\begin{array}{c}2201 \\
4\end{array}$ \\
\hline $\begin{array}{c}\text { OB } \\
\text { C }\end{array}$ & $\begin{array}{c}00,00 \\
88\end{array}$ & $\begin{array}{c}00,08 \\
91\end{array}$ & $\begin{array}{c}00,01 \\
04\end{array}$ & $\begin{array}{c}00,01 \\
17\end{array}$ & $\begin{array}{c}00,00 \\
96\end{array}$ & $\begin{array}{c}00,01 \\
05\end{array}$ & $\begin{array}{c}00,00 \\
90\end{array}$ & $\begin{array}{c}00,00 \\
82\end{array}$ & $\begin{array}{c}00,00 \\
92\end{array}$ & $\begin{array}{c}00,00 \\
74\end{array}$ & $\begin{array}{c}00,00 \\
75\end{array}$ & $\begin{array}{c}00,00 \\
94\end{array}$ & $\begin{array}{c}00,01 \\
01\end{array}$ & $\begin{array}{c}00,00 \\
95\end{array}$ & $\begin{array}{c}00,01 \\
07\end{array}$ \\
\hline
\end{tabular}


По результатам исследования видно, что происходят структурные сдвиги в динамике. Можно наблюдать, что показатель с 2000-2014 год возрастает.

Таблица 7. Результаты расчёта относительной величины структуры численности безработных в НО по отношению к РФ за

\begin{tabular}{|l|l|l|l|l|l|l|l|l|l|l|l|l|l|l|l|}
\hline & $\mathbf{2 2 0 0 0}$ & $\mathbf{2 2 0 0 1}$ & $\mathbf{2 2 0 0 2}$ & $\mathbf{2 2 0 0 3}$ & $\mathbf{2 2 0 0 4}$ & $\mathbf{2 2 0 0 5}$ & $\mathbf{2 2 0 0 6}$ & $\mathbf{2 2 0 0 7}$ & $\mathbf{2 2 0 0 8}$ & $\mathbf{2 2 0 0 9}$ & $\mathbf{2 2 0 1 0}$ & $\mathbf{2 2 0 1 1}$ & $\mathbf{2 2 0 1 2}$ & $\mathbf{2 2 0 1 3}$ & $\mathbf{2 2 0 1 4}$ \\
& & & & & & & & & & & & & & \\
\hline OB & 00,023 & 00,252 & 00,027 & 00,025 & 00,021 & 00,020 & 00,019 & 00,021 & 00,022 & 00,022 & 00,019 & 00,020 & 00,019 & 00,020 & 00,020 \\
C & 8 & 2 & 0 & 3 & 4 & 6 & 3 & 5 & 4 & 4 & 8 & 1 & 5 & 4 \\
5
\end{tabular}

По результатам исследования видно, что происходят структурные сдвиги в динамике. Можно наблюдать, что показатель с 2000-2014 год убывает.

Анализ показателей среднегодовой численности занятых в экономике РФ, ТО и ОО по видам экономической деятельности (тыс. чел.).

Таблица 1. Показатели среднегодовой численности занятых в экономике РФ по видам экономической деятельности за период

\begin{tabular}{|c|c|c|c|c|c|}
\hline & 2010 & 2011 & 2012 & 2013 & 2014 \\
\hline $\begin{array}{c}\text { Сельское хозяйство, } \\
\text { охота и лесное } \\
\text { хозяйство } \\
\end{array}$ & 6622 & 6565 & 6467 & 6364 & 6247 \\
\hline $\begin{array}{c}\text { Добыча полезных } \\
\text { ископаемых }\end{array}$ & 1054 & 1062 & 1080 & 1075 & 1064 \\
\hline Транспорт и связь & 5336 & 5354 & 5430 & 5420 & 5409 \\
\hline Образование & 5897 & 5785 & 5697 & 5570 & 5520 \\
\hline $\begin{array}{c}\text { Предоставление } \\
\text { прочих } \\
\text { коммунальных, } \\
\text { социальных и } \\
\text { персональных услуг }\end{array}$ & 2524 & 2526 & 2547 & 2520 & 2513 \\
\hline
\end{tabular}

В таблице 1 среднегодовая численность занятых в экономике РФ по виду экономической деятельности - «Сельское хозяйство, охота и лесное хозяйство» В 2010 году составило 6622, что на 5,7\% ниже, чем в 2014 году, показатель которого составлял 6247. «Добыча полезных ископаемых» В 2010 году составило 1054, что на 0,95\% выше, чем в 2014 году, показатель которого составлял 1064. «Транспорт и связь» В 2010 году составило 5336, что на 1,37\% выше, чем в 2014 году, показатель которого составлял 5409. «Образование» В 2010 году составило 5897, что на 6,39\% ниже, чем в 2014 году, показатель которого составлял 5520. «Предоставление прочих коммунальных, социальных и персональных услуг» В 2010 году составило 2524, что на $0,44 \%$ ниже, чем в 2014 году, показатель которого составлял 2513. Из расчётов можно сделать вывод, что наибольший рост наблюдается в виде экономической деятельности «Транспорт и связь» РФ в за период 2010-2014 гг. 
Таблица 2 . Показатели среднегодовой численности занятых в экономике ОО по видам экономической деятельности за период

\begin{tabular}{|c|c|c|c|c|c|}
\hline & $\mathbf{2 0 1 0}$ & $\mathbf{2 0 1 1}$ & $\mathbf{2 0 1 2}$ & $\mathbf{2 0 1 3}$ & $\mathbf{2 0 1 4}$ \\
\hline $\begin{array}{c}\text { Сельское хозяйство, } \\
\text { охота и лесное } \\
\text { хозяйство }\end{array}$ & 39,844 & 35,519 & 33,010 & 30,308 & 28,825 \\
\hline $\begin{array}{c}\text { Добыча полезных } \\
\text { ископаемых }\end{array}$ & 0,374 & 0,264 & 0,190 & 0,215 & 0,288 \\
\hline Транспорт и связь & 52,182 & 51,970 & 50,573 & 49,859 & 50,271 \\
\hline Образование & 67,483 & 64,704 & 63,695 & 68,087 & 68,360 \\
\hline $\begin{array}{c}\text { Предоставление } \\
\text { прочих }\end{array}$ & 23,099 & 22,529 & 22,888 & 21,084 & 20,538 \\
$\begin{array}{c}\text { коммунальных, } \\
\text { социальных и } \\
\text { персональных услуг }\end{array}$ & & & & \\
\hline
\end{tabular}

В таблице 2 среднегодовая численность занятых в экономике ОО по виду экономической деятельности - «Сельское хозяйство, охота и лесное хозяйство» В 2010 году составило 39,844, что на 27,7\% ниже, чем в 2014 году, показатель которого составлял 28,825. «Добыча полезных ископаемых» В 2010 году составило 0,374, что на $23 \%$ ниже, чем в 2014 году, показатель которого составлял 0,288. «Транспорт и связь» В 2010 году составило 52,182, что на 3,7\% ниже, чем в 2014 году, показатель которого составлял 50,271. «Образование» В 2010 году составило 67,483, что на 1,3\% выше, чем в 2014 году, показатель которого составлял 68,360. «Предоставление прочих коммунальных, социальных и персональных услуг» В 2010 году составило 23,099, что на 11\% ниже, чем в 2014 году, показатель которого составлял 20,538.

Из расчётов можно сделать вывод, что рост наблюдается в виде экономической деятельности «Образование» ОО за период 2010-2014 гг.

Таблииа 3. Показатели среднегодовой численности занятых в экономике ТО по видам экономической деятельности за период с 2010-20142.

\begin{tabular}{|c|c|c|c|c|c|}
\hline & $\mathbf{2 0 1 0}$ & $\mathbf{2 0 1 1}$ & $\mathbf{2 0 1 2}$ & $\mathbf{2 0 1 3}$ & $\mathbf{2 0 1 4}$ \\
\hline $\begin{array}{c}\text { Сельское хозяйство, } \\
\text { охота и лесное } \\
\text { хозяйство }\end{array}$ & 14,5 & 12,8 & 12,0 & 11,4 & 10,8 \\
\hline $\begin{array}{c}\text { Добыча полезных } \\
\text { ископаемых }\end{array}$ & 10,2 & 11,0 & 11,3 & 11,8 & 11,9 \\
\hline Транспорт и связь & 27,4 & 25,9 & 25,7 & 24,8 & 24,4 \\
\hline Образование & 48,9 & 47,2 & 46,6 & 46,0 & 46,0 \\
\hline $\begin{array}{c}\text { Предоставление } \\
\text { прочих } \\
\text { коммунальных, } \\
\text { социальных и } \\
\text { персональных услуг }\end{array}$ & 8,8 & 8,7 & 8,7 & 8,5 & 8,5 \\
\hline
\end{tabular}

В таблице 3 среднегодовая численность занятых в экономике ТО по виду экономической деятельности - «Сельское хозяйство, охота и лесное хозяйство» 
В 2010 году составило14,5, что на 25,5\% ниже, чем в 2014 году, показатель которого составлял 10,8. «Добыча полезных ископаемых» В 2010 году составило 10,2, что на $16 \%$ выше, чем в 2014 году, показатель которого составлял 11,9. «Транспорт и связь» В 2010 году составило 27,4, что на 11\% ниже, чем в 2014 году, показатель которого составлял 24,4. «Образование» В 2010 году составило 48,9 , что на 6 \% ниже, чем в 2014 году, показатель которого составлял 46,0. «Предоставление прочих коммунальных, социальных и персональных услуг» В 2010 году составило 8,8, что на 4 \% ниже, чем в 2014 году, показатель которого составлял 8,5.

Из расчётов можно сделать вывод, что рост наблюдается в виде экономической деятельности «Добыча полезных ископаемых» ТО за период 2010-2014 гг.

Таблий 4. Результаты расчёта относительной величины динамики по виду экономической деятельности - Сельское хозяйство, охота и лесное хозяйство» за период 2010-2015 г.

\begin{tabular}{|c|c|c|c|c|c|}
\hline & $\mathbf{2 0 1 0}$ & $\mathbf{2 0 1 1}$ & $\mathbf{2 0 1 2}$ & $\mathbf{2 0 1 3}$ & $\mathbf{2 0 1 4}$ \\
\hline $\begin{array}{c}\text { ОВД } \\
\text { базисный }\end{array}$ & - & 0,9914 & 0,9766 & 0,9610 & 0,9434 \\
\hline ОВД цепной & - & 0,9914 & 0,9851 & 0,9841 & 0,9816 \\
\hline
\end{tabular}

По результатам исследования динамики численность занятых в экономике РФ по виду экономической деятельности - «Сельское хозяйство, охота и лесное хозяйство» за период 2010-2015 гг., уменьшилась. Можно увидеть, что за 4 года наименьший показатель составил 0,94 тыс. человек.

Таблица 5 . Результаты расчёта относительной величины динамики среднегодовая численность занятых в экономике РФ по виду экономической деятельности - «Добыча полезных ископаемых» за период 2010-2015 г.

\begin{tabular}{|c|c|c|c|c|c|}
\hline & $\mathbf{2 0 1 0}$ & $\mathbf{2 0 1 1}$ & $\mathbf{2 0 1 2}$ & $\mathbf{2 0 1 3}$ & $\mathbf{2 0 1 4}$ \\
\hline $\begin{array}{c}\text { ОВД } \\
\text { базисный }\end{array}$ & - & 1,0076 & 1,0247 & 1,0210 & 1,0095 \\
\hline ОВД цепной & - & 1,0076 & 1,0169 & 0,9954 & 0,9898 \\
\hline
\end{tabular}

По результатам исследования динамики численность занятых в экономике РФ по виду экономической деятельности - «Добыча полезных ископаемых» за период 2010-2015 гг., увеличилась. Можно увидеть, что за 4 года наименьший показатель составил 1,0095 тыс. человек.

Таблица 6 Результаты расчёта относительной величины динамики среднегодовая численность занятых в экономике РФ по

\begin{tabular}{|c|c|c|c|c|c|}
\multicolumn{6}{c|}{ виду экономической деятельности - «Транспорт и связь за период 2010-2015 г. } \\
\hline $\begin{array}{c}\text { ОВД } \\
\text { базисный }\end{array}$ & $\mathbf{2 0 1 0}$ & $\mathbf{2 0 1 1}$ & $\mathbf{2 0 1 2}$ & $\mathbf{2 0 1 3}$ & $\mathbf{2 0 1 4}$ \\
\hline ОВД цепной & - & 1,0034 & 1,0176 & 1,0157 & 1,0137 \\
\hline
\end{tabular}


По результатам исследования динамики численность занятых в экономике РФ по виду экономической деятельности - «Транспорт и связь» за период 20102015 гг., увеличилась. Можно увидеть, что за 4 года наименьший показатель составил 1,0137 тыс. человек.

Таблица 7. Результаты расчёта относительной величины динамики среднегодовая численность занятых в экономике РФ по виду экономической деятельности - «Образование» за период 2010-2015 2.

\begin{tabular}{|c|c|c|c|c|c|}
\hline & $\mathbf{2 0 1 0}$ & $\mathbf{2 0 1 1}$ & $\mathbf{2 0 1 2}$ & $\mathbf{2 0 1 3}$ & $\mathbf{2 0 1 4}$ \\
\hline $\begin{array}{c}\text { ОВД } \\
\text { базисный }\end{array}$ & - & 0,9810 & 0,9661 & 0,9445 & 0,9361 \\
\hline ОВД цепной & - & 0,9810 & 0,9848 & 0,9777 & 0,9910 \\
\hline
\end{tabular}

По результатам исследования динамики численность занятых в экономике РФ по виду экономической деятельности - «Образование» за период 2010-2015 гг., снизилось. Можно увидеть, что за 4 года наименьший показатель составил 0,9361 тыс. человек.

Таблий 8.

Результаты расчёта относительной величины динамики «Предоставление прочих коммунальных, сочиальныхх и персональных услуг» за период 2010-2015 г.

\begin{tabular}{|c|c|c|c|c|c|}
\hline & $\mathbf{2 0 1 0}$ & $\mathbf{2 0 1 1}$ & $\mathbf{2 0 1 2}$ & $\mathbf{2 0 1 3}$ & $\mathbf{2 0 1 4}$ \\
\hline ОВД базисный & - & 1,0008 & 1,0091 & 0,9984 & 0,9956 \\
\hline ОВД цепной & - & 1,0008 & 1,0083 & 0,9893 & 0,9972 \\
\hline
\end{tabular}

По результатам исследования динамики численность занятых в экономике «Предоставление прочих коммунальных, социальных и персональных услуг» можно увидеть, что за 4 года наименьший показатель составил 0,9956 тыс. человек.

Таблица 9.

Результаты расчёта коэффициентов корреляциии по виду экономической деятельности «Сельское хозяйство, охота и лесное хозяйство» за период 2010-2014 г.

\begin{tabular}{|c|c|c|c|}
\hline & ТО и РФ & ОО и РФ & ОО и ТО \\
\hline $\begin{array}{c}\text { Коэффициент } \\
\text { корреляции }\end{array}$ & 1,0 & 1,0 & 1,0 \\
\hline $\begin{array}{c}\text { Коэффициент } \\
\text { корреляции }\end{array}$ & 3,7 & 3,7 & 3,6 \\
\hline
\end{tabular}

Связь между показателями численности занятых в экономике по виду экономической деятельности - «Сельское хозяйство, охота и лесное хозяйство» за период 2010-2014 г., в среднем нелинейная, имеется сильная корреляционная зависимость. Сильная корреляционная зависимость наблюдается во всех показателях ТО, РФ и ОО. 
Таблица 10.

Результаты расчёта коэффициентов корреляции по виду экономической деятельности «Добыча полезных ископаемых» за период 2010-2014 г.

\begin{tabular}{|c|c|c|c|}
\hline & ТО и РФ & ОО и РФ & ОО и ТО \\
\hline $\begin{array}{c}\text { Коэффициент } \\
\text { корреляции }\end{array}$ & 0,8 & 0,3 & 0,4 \\
\hline $\begin{array}{c}\text { Коэффициент } \\
\text { корреляции }\end{array}$ & 3,7 & 4,5 & 3,4 \\
\hline
\end{tabular}

Связь между показателями численности занятых в экономике по виду экономической деятельности - «Добыча полезных ископаемых» за период 20102014 гг, в среднем нелинейная, а также присутствует слабая корреляционная зависимость в ОО и РФ и ОО и ТО, но в ТО И РФ корреляционная зависимость сильная . Можно сделать вывод, что самая слабая корреляционная зависимость наблюдается в ОО и РФ.

Таблица 11

Результаты расчёта коэффищиентов корреляции по виду экономической деятельности «Транспорт и связь» за период 2010-2014 г.

\begin{tabular}{|c|c|c|c|}
\hline & ТО и РФ & ОО и РФ & ОО и ТО \\
\hline $\begin{array}{c}\text { Коэффициент } \\
\text { корреляции }\end{array}$ & 0,3 & 0,3 & 0,9 \\
\hline $\begin{array}{c}\text { Коэффициент } \\
\text { корреляции }\end{array}$ & 3,9 & 4,5 & 3,8 \\
\hline
\end{tabular}

Связь между показателями численности занятых в экономике по виду экономической деятельности - «Транспорт и связь» за период 2010-2014 г., нелинейная, но, тем не менее, имеется сильная корреляционная зависимость только в ОО и ТО, а в ТО и РФ; ОО и РФ, наблюдается слабая корреляционная зависимость. Можно сделать вывод, что сильная корреляционная зависимость наблюдается только у показателей ТО и ОО.

Таблица 12

Результаты расчёта коэффициентов коррелячуии по виду экономической деятельности «Образование» за период 2010-2014 г.

\begin{tabular}{|c|c|c|c|}
\hline & ТО и РФ & ОО и РФ & ОО и ТО \\
\hline $\begin{array}{c}\text { Коэффициент } \\
\text { корреляции }\end{array}$ & 0,8 & 0,3 & 0,4 \\
\hline $\begin{array}{c}\text { Коэффициент } \\
\text { корреляции }\end{array}$ & 3,0 & 4,1 & 3,9 \\
\hline
\end{tabular}

Связь между показателями численности занятых в экономике по виду экономической деятельности - «Образование» за период 2010-2014 г., нелинейная, но, тем не менее, имеется сильная корреляционная зависимость только в ТО и РФ; ОО и РФ, ОО и ТО наблюдается слабая корреляционная 
зависимость. Можно сделать вывод, что сильная корреляционная зависимость наблюдается только у показателей ТО и РФ.

Таблица 13.

Результаты расчёта коэффициентов корреляции по виду экономической деятельности «Предоставление прочих коммунальных, сочиальных и персональных услуг» за период 2010-2014

\begin{tabular}{|c|c|c|c|}
\hline & ТО и РФ & ОО и РФ & ОО и ТО \\
\hline $\begin{array}{c}\text { Коэффициент } \\
\text { корреляции }\end{array}$ & 0,8 & 0,8 & 0,6 \\
\hline $\begin{array}{c}\text { Коэффициент } \\
\text { корреляции }\end{array}$ & 3,4 & 3,5 & 4,4 \\
\hline
\end{tabular}

Связь между показателями численности занятых в экономике по виду экономической деятельности - «Предоставление прочих коммунальных, социальных и персональных услуг» за период 2010-2014 г., нелинейная, но, тем не менее, имеется сильная и средняя корреляционная зависимость. Можно сделать вывод, что средняя корреляционная зависимость наблюдается только у показателей ОО и ТО.

1. Аширов Д. А. Управление человеческими ресурсами - М.; Мэрст ДС, 2009. - 194c.

2. Кучеренко В.3.Применение методов статистического анализа,2006.-С. 153-157.

3. Борисов Е. Ф. Экономическая теория: учеб. - 2-е изд., перераб. И доп. - М.: ТК Велби, Изд-во Проспект, 2008

4. Буланов В. С. Методологические вопросы исследования рынка труда// Общество и экономика. $-2010 .-210 \mathrm{c}$.

5. Елисеева И.И. Статистика,2012.-С. 41-44. 